\title{
An Ecosystems Analysis of How Sales Managers Develop Salespeople
}

Business ecosystems were first introduced by Moore (1996) as a way to enhance the study of networks within businesses. At a macro-level, the approach views firms as interconnected parts of a larger environment, providing a useful perspective on global firms where the 'pull' of corporate culture may counteract differing national contexts. More recently, the approach has been used at a micro-level to understand the interdependencies that exist between service providers and customers in the value co-creation process (Vargo and Lusch 2015); systemic interactions between buyers and sellers have been widely researched. The ecological systems approach has also been used to depict and understand the roles, interactions and interdependencies that occur within entrepreneurship (Spigel, 2017), its impact on strategy development (Jacobides et al., 2018), and even international career mobility (Baruch et al., 2016). Yet, despite extensive research into sales and into sales leaders, the inner workings of the sales ecosystem remain largely opaque. Ecological systems theory can provide valuable insights into the relationship between sales managers and their subordinate salespeople, which leads to a better understanding of that network of interdependencies.

The leadership behaviors of sales managers have been widely studied in the sales management literature for many years (see Peesker et al., 2019 for a recent review). The current study is unique in that we take a systemic approach that draws from Bronfenbrenner's (1979) ecological theory. This approach provides an enhanced view of salespeople's personal microsystems and reveals how leader behaviors and the types of interdependencies within the sales ecosystem can develop salespeople such that they perform at a higher level. The use of an ecosystem metaphor to describe the inner workings and network connections involved in a business helps provide a framework for understanding the behaviors and relationships that exist within - as well as across - industries (Adomavicius et al., 2006). In fact, given that we examine 36 sales professionals from 12 countries spanning four continents, the study helps contextualize intraorganizational dynamics in an international context.

Within sales organizations, salespeople operate within an ecosystem that includes social relationships both within and outside the organizations (Hartmann et al., 2017). The link between commercial ecosystems and performance has been studied at the level of the firm, often in the technology field (e.g. Eckhardt et al., 2018). This study explores the sales ecosystem associated with a global technology firm, examining the sales manager-salesperson relationship as one of the elements that enable salespeople to develop and thrive within that sales ecosystem.

The goal of this study is to identify specific leader behaviors (exhibited by sales managers) that are most relevant to developing salespeople and enabling performance. By taking an ecological perspective on the salesperson-sales manager relationship, the study identifies ways that salespeople access resources and perform in the sales ecosystem. The study of sales from this perspective can be very important for providing more structure to sales organizations through the comprehensive understanding of sales leaders and behavior, pointing towards a link to sales performance. The qualitative data provide an especially rich, in-depth picture of what these leader behaviors are and how they operate. Further, the study compares high performing salespeople to low performers to consider the differences in how more / less developed salespeople might benefit from a sales manager's leadership. Finally, we outline areas for future 
research that could explore the links between the sales and customer ecosystems and sales performance outcomes.

\section{Literature Review}

Sales organizations are required to operate in an environment that is highly dynamic and interconnected at all levels of aggregation (Turber et al., 2015). Similar to a biological ecosystem, a sales ecosystem is an economic community that has as its foundation the interaction between individuals and organizations (Moore, 1996). The use of an ecosystems metaphor to describe the inner workings and network connections involved in a business provides a way to enhance the study of business networks by seeing the firm as an interconnected part of its larger environment (Moore, 1996). Moore's research highlighted the role of the individual firm and stresses the importance of the collective health of the system in which the firm is rooted (Moore, 1996).

The theory has been explored by researchers in digital, entrepreneurial, social and technological ecosystems to help provide a framework for understanding the behaviors and relationships that exist within and across industries (Adomavicius et al., 2006). The use of an ecosystems metaphor when discussing a business network opens up an alternate way of looking at the structure, interactions, and exchanges amid organizations (Anggraeni et al., 2007). Firms need to be aware of their internal landscape, but also need to have the ability to interact with the external environment. An ecosystems perspective provides firms more strategic flexibility and a better idea of how their network of internal and external factors interact (Anggraeni et al., 2007).

Like biological ecosystems, business ecosystems are characterized by their large number of loosely interconnected participants, both internally and externally, who rely on one another for their mutual effectiveness and survival. This is why the ecosystems metaphor is so crucial in today's world of business research (Iansiti and Levien, 2004). Bronfenbrenner's (1979) ecological systems theory provides a framework through which the interactions among the individuals that participate in the system can be viewed.

Within a given ecosystem, Bronfenbrenner (1979) describes five nested structures: microsystems, mesosystems, exosystems, macrosystems and chronosystems. Clearly, all five of these subsystems play an important role in how successfully a salesperson performs. However, our chief interest is the impact that sales managers have on the microsystem and mesosystem, the two nested structures closest to salespeople. By concentrating our research on the sales context for a single, very large technology company at a particular point in time, we provide an in-depth study of the sales microsystems and mesosystems within that firm and hold constant the exosystem, macrosystem, and chronosystem. The focus of this study is on how sales managers can enhance the microsystems and mesosystems of their salespeople. Consistent with Kapoor's (2018) approach, we explore the complementarities and interdependencies among actors within these systems, using sales performance as our proxy for how those interactions influence the user value proposition.

A single salesperson has several microsystems. For example, a salesperson's network of interactions for each customer is arguably a separate microsystem. In business-to-business sales, buying centers are large; so, it is generally beneficial for a salesperson to have a large network of 
contacts with respect to each customer organization. Having a number of interactions and connections with people inside the customer organization helps the salesperson better understand customer needs. Of course, this also serves them well because they maintain top-of-mind awareness with customers, and become the go-to person to help the customer with solutions relevant to what they sell.

Another microsystem for salespeople is the network that includes their fellow salespeople and their sales manager. Increasingly, members of sales organizations work as a team; so, interactions and connections inside this microsystem can occur on a regular basis, often at sales meetings led by the sales manager. Of course, salespeople working in the same environment can learn a lot from each other, especially rookie salespeople that connect to experienced, top performers. This approach to a sales ecosystem is consistent at the intrafirm level with the definition proposed by Bogers et al. (2019) of an ecosystem as exhibiting shared goals, interdependence between members, and a network of relationships.

Yet another microsystem for salespeople includes their relationships with non-sales coworkers throughout the firm. These can include engineers, supply chain managers, marketers, and others. Research has shown that the interactions among these intra-organizational resources are a key component of salespeople's success (Bolander et al., 2015). Salespeople are more successful when developing an increased number of relationships with internal contacts within their own firm (Flynn, 2003) and with external contacts within a given customer firm (Houston et al., 1992; Sheth, 1996). In other words, an effective microsystem helps salespeople solve customer problems and provide better service to their client base.

The mesosystem, which is the second level in the ecosystem (Bronfenbrenner, 1979), is defined as the interaction of the microsystems of one individual. For example, a salesperson would have separate networks for two different customers. However, if those two customers talk with each other and discuss the salesperson, that happens at the mesosystem level. Note that a given person generally has many microsystems, but just one mesosystem.

\section{Connection between ecosystems and leadership}

We argue that the current study is the first to connect sales leadership behaviors to ecological systems theory, but of course much academic research has examined how leadership of first-line sales managers can enhance salesperson outcomes (e.g. Bande et al., 2016; Churchill et al., 1985; Ingram et al., 2005; Lee and Welliver, 2018; MacKenzie et al., 2001; Peesker et al., 2019; Rich, 1998). This past literature draws from a number of leadership theories, including transformational leadership (Bass, 1985; Inyang et al., 2018), servant leadership (Liden et al., 2008; Bande et al., 2015), path-goal theory (Hackman and Oldham, 1974), leader-member exchange theory (Dansereau et al., 1975), ethical leadership (Brown et al., 2005), self-leadership (Singh et al., 2017).

Although past sales leadership research has not explicitly referenced ecological systems theory, some of these studies do discuss the sales managers' role in developing their salespeople. For example, Bande et al. (2015) explored the influence of the relatively recent theory of servant leadership on salespeople. Servant leaders are concerned first and foremost with their subordinates' personal development. These leaders enhance their salespeople's self-efficacy and intrinsic motivation by harnessing and supporting more adaptive and proactive employee behaviors (Bande et al., 2015). This emphasis on personal development allows their employees 
to cultivate new skills through engagement with more than just the organization (Liden et al., 2008), thus expanding their sales ecosystems.

When sales managers trust and respect their subordinates, salespeople typically return the favor (Rich, 1998). This mutually supportive environment is vital to the effectiveness of sales managers' leadership (Bande et al., 2015). Salespeople react positively to sales managers that are trustworthy role models (Rich, 1998). Contrary to the conventional belief that more experienced salespeople should be given autonomy in order to focus the leadership time on coaching junior salespeople, Rapp et al. (2020) recently found that sales managers are wise to work just as closely (if not more so) with their more experienced sales teams.

Clearly, sales managers can play important roles in helping all of their salespeople form more and better connections with others - including their fellow salespeople, internal (non-sales) colleagues, and individuals within the customer firm. Past research shows that these connections strengthen resource links and establish a structurally sound work environment (Bolander et al., 2015; Ingram et al., 2005).

The goal of this study is to identify specific leader behaviors (exhibited by sales managers) that are most relevant to developing salespeople, enabling performance, and creating a healthy sales ecosystem. We do this in an exploratory manner using qualitative data gathered through in-depth interviews. This qualitative analysis results in rich data that provide an in-depth picture that is particularly useful for exploring how and why things have happened (Lincoln and Guba, 1985). The methodology is explained in the next section.

\section{Methodology}

The data analyzed for this study were gathered through in-depth interviews with a sample of 36 sales professionals employed at a single global information technology (IT) company, which operates in the complex value-creating enterprise software industry. This approach meant that the phenomenon studied was in context and multiple perspectives rooted in this specific context could be explored (Creswell, 2013; Ritchie et al., 2014). The specific sales environment of the IT company is characterized by uncertain market conditions and rapid technological change. The research was global in nature, with sales teams focused on business-to-business 'outside' (client) sales where relationship-building is very important.

All respondents were over 30 years old; more than half were between the ages of 40 and 50 , reflecting the seniority of this type of sales role. Most were based in Europe (50\%), with 31\% based in the Commonwealth (United Kingdom, Canada, and Australia), $14 \%$ in Asia, and 6\% in the Middle East. Respondents had significant work experience, with none having fewer than 5 years and 39\% having over 21 years. All 36 sales professionals had bachelor's degrees, and 20 of them had attained some type of master's degree.

We used a purposive sample (Guarte and Barrios, 2006) consisting of both sales managers $(n=12,33 \%)$ and salespeople $(n=24,67 \%)$. The majority of the sales managers ( 9 out of 12$)$ were delegates of a master's program at a global business school. All managers had experience directly managing salespeople, ranging from 3 to 20 years of experience in sales leadership, the average being just under 9 years of leading salespeople. These sales managers were asked to 
invite a range of their subordinate salespeople (from low to high performers) to participate in the research.

Semi-structured interviews were selected as the method for data collection as they provide a flexible but structured method of obtaining a rich set of data for analysis (Easterby-Smith et al., 2008; Ritchie et al., 2014). This method enables respondents to share experiences and feelings, leading to a deeper understanding of the phenomenon of interest (Deeter-Schmelz et al., 2008; Fontana and Frey, 1994), which in this case is the ecosystem. Each semi-structured interview lasted between 50 and 110 minutes; in total, we recorded over 47 hours of interviews. The interviews were transcribed verbatim and uploaded to NVivo software for analysis, where separate statements were coded using the Miles and Huberman (1994) coding system. Although existing leadership theory provided a theoretical model to guide the approach of labeling leader behaviors, the development of ideas and constructs flowed from the research data using a grounded approach (Charmaz, 2006). Procedures employed by established qualitative researchers were followed (Easterby-Smith et al., 2008; Strauss and Corbin, 1998). A test for interrater reliability, which determines the extent to which a sample of data would be coded in a similar way by another academic, produced a Cohen's Kappa Coefficient of 0.75 - indicating substantial interrater agreement that demonstrates a robustness in the coding process.

The interview protocol began by asking each respondent to identify leader behaviors that they see as enabling salesperson performance. Their answers were followed by a series of open-ended questions to encourage elaboration and to gain an understanding of why they believed the various leader behaviors were effective.

\section{Findings}

Based on this coding procedure and qualitative analysis, the interviews generated a total of 1,908 references to leader behaviors. These references were coded into the following nine distinct leader behaviors: coaching, collaborating, championing, customer engaging, challenging, creating vision, candidate recruiting, inspiring, and rewarding (Table 1). Recall these are leader behaviors that our sample of sales professionals identified as being important for sales managers to exhibit in order to enable performance of their salespeople.

\section{[ Insert Table 1 here ]}

Coaching. As seen in Table 1, coaching was the most frequently-referenced leader behavior by far. Specifically, the coding process resulted in $33.0 \%$ (630 out of 1,908$)$ of the leader behaviors labeled as coaching.

As is common with qualitative data, the transcribed interviews revealed a richness of information that is difficult to extract via typical descriptive survey techniques. One interesting discovery, for example, is how coaching is most effective when the sales manager facilitates self-discovery by asking the right questions. This was a theme that emerged from several similar comments. As one salesperson said about coaching, "I have this notion that I actually have got the answer myself, I just need the right questions to answer.” In a similar vein, a sales manager said, “...a coaching attitude is the ability to ask questions and help the person find their own way and apply their own change theories which is more powerful than only telling or mentoring the sales guys." 
Interviews indicated that the objective of coaching was typically to improve aspects of the sales process - especially behaviors that are leading indicators of success. This includes guidance on effective strategies for lead generation, making sales calls, demonstrating the product, handling objectives, and other input behaviors that go into making a sale. Conversely, the responses indicated that coaching should be less focused on lagging indicators, such as gross margin, sales volume, market share, and number of deals won or lost.

A frustration associated with coaching was that sales managers did not have enough time for it. That is, sales managers felt that they could not take a long-term perspective of developing salespeople through coaching because they were under constant pressure to attain more immediate goals (i.e., quarterly results). For example, one sales manager said:

"At the end of the quarter, the 6 weeks within the quarter, all the nice speech about leadership and coaching and all these things simply disappear and at "IT company" you move back to fight and fire. Unless you achieve your numbers the financial markets will shout. So the priorities are shifted to the transactional model again". (Sales Manager/Europe)

Customer engaging. Customer engaging was also identified as a key leader behavior by our sample. As seen in Table 1, the coding process resulted in $12.1 \%(230$ out of 1,908$)$ of the leader behaviors labeled as customer engaging.

Customer engaging behavior is primarily about sales managers taking the time to become familiar with the customers of their salespeople. This is reflected in the following response:

"I find that many times, a sales manager's role is a lot about just feeding up numbers to go to the organization ... but it should be that the sales manager should know at least at a conversational level what's happening in each of their accounts in which their salespeople are involved." (Salesperson/Europe)

Note that this does not necessarily involve the sales manager directly interacting with their salespeople's customers, but it could. That is, some respondents suggested that sales managers can help them by being present for tough conversations with customers, by inserting themselves in challenging customer negotiations, and/or by providing assistance in closing big sales. This aspect of customer engaging that involves direct interaction with customers clearly overlaps with coaching because it tends to happen when the sales manager is with the salesperson on a call. However, customer engaging necessarily involves the sales managers becoming familiar with the nuances of their salespeople's customers; coaching does not always involve this.

Salespeople generally believed that the presence of the manager tended to lend additional credibility to their efforts and interactions with customers. In fact, salespeople valued customer engagement with the sales manager at more than twice the rate as sales managers. So, salespeople saw significant value in having leaders that engaged with their customers. At the same time, respondents made it clear that salespeople (not sales managers) should take the lead in the selling process.

Collaborating. Collaborating was a main theme and represented the second most popular leader behavior identified by our sample. As seen in Table 1, the coding process resulted in $20.3 \%$ (387 out of 1,908 responses) of the leader behaviors labeled as collaborating. 
Collaborating can occur when sales managers organize meetings, conference calls and other activities that allow salespeople to directly interact with each other. These interactions may include discussions about best sales practices, sales wins, sales losses and internal and external networking. Brainstorming and generating new ideas are also important aspects to this leader behavior. Interestingly, the data in Table 1 suggest that salespeople value the act of collaborating at a higher level than sales managers.

As shown by the following response, collaborating behavior enables salespeople both to give and to receive help:

I hope I'm building sales excellence by encouraging learning from others, because what somebody does in one part may be relevant in a slightly different way or applied in a different way I should say to another part. We can all be successful when we learn from each other. (Sales Manager/Commonwealth)

Collaboration relates to teamwork. Indeed, the sales professionals in our sample emphasized the benefits of working together as a team. This is often difficult to do given that salespeople tend to live and work in different locations and do not see each other every day. Sales managers, however, can create this team dynamic by exhibiting collaboration. Further, when salespeople interact as a team and learn from each other, this frees up time for sales managers to focus on other key aspects of their job.

Championing. Championing was the third most referenced leader behavior. Specifically, the coding process labeled $16.7 \%$ (319 out of 1,908) of the references as championing.

Championing is about sales managers protecting their salespeople from unnecessary busywork so they can better focus on selling. Sales managers can do this by solving internal problems for their salespeople and by being strong advocates for their salespeople throughout the organization. As one sales manager said:

"I think the higher up you go into the sales management chain the more important it is for those sales managers to work across the organization to fix the problems that are getting in the way of you selling." (Sales Manager/Asia Pacific)

This is important because salespeople's interaction with customers and business partners gives them access to a significant amount of marketplace knowledge that is essential to the planning function of the organization. This can lead to colleagues from multiple divisions throughout the firm making information requests from the sales force. Responding to all these requests can distract the sales team from their core job - selling. Salespeople discussed how they need shelter from these types of requests and appreciated leaders that engaged in protecting, clearing roadblocks, obtaining approvals, providing escalations, and reducing administration.

\section{Other leader behaviors}

As shown in Table 1, the following five leader behaviors were also mentioned by our sample as being important contributors toward sales performance: challenging, creating vision, candidate recruiting, inspiring, rewarding. However, the number of references to these leader behaviors dropped off sharply compared to the number of references to coaching, collaborating, championing, and customer engaging. So, due to this drop-off - and due to space constraints - 
the primary focus is on the four leader behaviors that were mentioned most frequently. We encourage future researchers to examine these other leader behaviors more closely.

\section{Potential relational elements}

As we explored and analyzed the data in the coding process, four relational elements that link sales managers and salespeople emerged: trust, confidence, optimism, and resilience. Specifically, there were 59 references to trust, 35 references to confidence, 16 references to optimism, and 9 references to resilience. Responses suggest that these variables are outcomes of the key leader behaviors and that they might play a mediating role between the leader behaviors and performance. We see these variables as being part of the reason why the leader behaviors are effective at developing salespeople. Although space constraints prohibit a more detailed analysis and discussion of these four relational elements, we do see this as another opportunity for future researchers. Sample quotes for trust, confidence, optimism and resilience are included in Table 2.

\section{[ Insert Table 2 about here ]}

\section{Differences between high performing and low performing salespeople}

Table 3 shows the data for references to both leader behaviors and relational elements across high and low performing salespeople. Graphical representations of these references are shown in Figure 1 and Figure 2. These are the responses of the 8 highest performing salespeople and the 8 lowest performing salespeople in the sample. Data for the middle performing salespeople and the sales managers are not included in this analysis. These salespeople were split into high and low performing groups based on a performance ranking provided by their sales managers. Table 3 and Figures 1 and 2 show that high performers generally provided more references to leader behaviors than did the low performers. That is, the high achievers appeared to be stronger at reflecting their experiences by providing more references to leader behaviors that enabled performance. This is especially true for the coaching and customer engaging leader behaviors. Interestingly, the high performers referred to coaching almost twice as much as did low performers - just as sales managers were much more likely to discuss coaching than were salespeople. As such, high performing salespeople seemed to be communicating more like sales managers than were low performing salespeople. This provides more evidence of the importance of coaching. Finally, high performers were also much more likely to reference the four relational elements compared to low performers (see Figure 2).

\section{[ Insert Table 3 here] [ Insert Figure 1 here ] [ Insert Figure 2 here ]}

\section{Discussion}

The ensuing discussion will focus on how the key leader behaviors that emerged from the qualitative analysis operate in the sales ecosystem toward developing salespeople. The findings confirm that enabling sales performance goes hand-in-hand with developing salespeople. In fact, the nature of our qualitative data provides insight into how and why these leader behaviors are effective in developing salespeople. Specifically, the analysis reveals ways that these leader behaviors enhance both the microsystems and mesosystems of salespeople. 
Coaching: As explained in the literature review, the network of individuals that includes a salesperson's fellow salespeople and their sales manager is a distinct microsystem. The extent to which this microsystem plays an influential role in the development of salespeople corresponds to the coaching abilities of the sales manager and the receptiveness of the salesperson. This is logical given that coaching is focused on the relationship between the salesperson and sales manager.

Coaching was the most referenced leader behavior in our sample (see Table 1), suggesting that this microsystem plays an important role in developing salespeople and enabling performance, especially if sales managers provide individualized, hands-on assistance and instruction to help their salespeople recognize opportunities to improve their job performance.

Our sample's praise for coaching among practitioners is not surprising given that this leader behavior is established as an important leader behavior in a number of academic leadership theories (e.g., Bass, 1985; Boehnke et al., 2003; Howell and Avolio, 1993; Rich, 1998; Shannahan et al., 2013).

Their comments suggested that coaching provides opportunities for growth and learning. This was expressed by both sales managers and salespeople as demonstrated in the following extracts:

"What I really appreciate is someone who can bring a different perspective, and can get me a different way to see things, or can teach me a different way to approach situation. They can deliver this experience to me in a way that is going to make think, rather than just give a recipe for success". (Sales Manager/Asia Pacific)

"Showing an actual interest in your people (as a coach), showing an actual interest and understanding an underlying situation on what's going on behind the lines I would say that is, that would be an empathetic perspective... and that can help enable sales performance”. (Salesperson/Commonwealth)

Our qualitative analysis of these references led to the following construct definition for this leader behavior: coaching by a sales manager is the behavior of providing individualized, handson assistance and instruction to help salespeople recognize opportunities to improve their job performance.

Customer engaging: Each relationship between a salesperson and particular customer is the focal point of another distinct microsystem. It appears that, to be successful, a salesperson needs to play a prominent role in a healthy number of these microsystems. Moreover, this is not just about the quantity of 'customer engaging' microsystems; it is also about the quality of the interactions. Our findings show that customer engaging behaviors by sales managers increases not only the number of these networks, but also the quality of them.

The comments about this leader behavior reveal how the sales manager can play a central role in this customer-centered microsystem. One high performing salesperson said the following about customer engaging:

"If the million-dollar deal is not moving, it's because somebody within the (customer) organization is not understanding the value proposition that we're putting across. So either we are not positioning right, or we are talking to the wrong people. And this is where then the issues can be and sales leaders should help". (Salesperson/Asia Pacific) 
In other words, sales managers can help their salespeople understand who in the customer firm to talk to, and how to position the product in a way that demonstrates its value to each customer. This can only happen, however, if the sales manager invests the time and energy to understand the unique needs of the particular customer.

Respondents indicated that sales managers are especially helpful in engaging higher-level executives in the customer firm. That is, sales managers can use their superior position and rank to help the salesperson connect to $\mathrm{C}$-level executives of the customer firm. C-level executives are more likely to meet with other high-level executives than with entry-level salespeople.

We found that effective implementation of this behavior was crucial, as the salesperson respondents did not want their manager taking control in the account call. This is consistent with research that found that salespeople do not value leaders who do the selling for them (DeeterSchmelz et al., 2008), and it is important for sales managers to find the optimal engagement of this behavior so that this engagement is not perceived as micromanagement.

Our qualitative analysis of these references led to the following construct definition for this leader behavior: customer engaging is behavior by the sales manager that involves researching and/or interacting with customers to help progress sales deals, developing executive-customer relationships, and demonstrating to salespeople how to provide value effectively to customers.

Collaborating: The leader behavior that is arguably the most relevant to creating a strong sales ecosystem is collaborating. This leader behavior is already established in the sales literature as one that benefits salespeople (Ingram et al., 2005; Dixon and Tanner, 2012; Üstüner and Godes, 2006). Sales managers engage in collaborating by organizing, facilitating, and leading group activities in which the salespeople are encouraged to interact with and learn from each other as they solve problems as a team. Such intermingling leads to an interaction of the various microsystems of each salesperson. In other words, collaborating behavior by the sales manager enhances the mesosystem, as it is all about connecting microsystems with other microsystems. It helps salespeople find the information they need within the ecosystem.

Collaborating is the one leader behavior where the actual term ecosystem appeared in the comments of our sample. The following respondent argues that this collaborative network should contain both sales and non-sales colleagues that are internal, as well as external resources (such as industry experts) that work outside of the firm:

"What is key to a great performer is the ability to work in teams. We need to work first with partners outside of IT company and internally you need to be able to orchestrate the various resources that you have at your disposal. If you look at the way we operate at IT company, we have built an ecosystem of supporting roles, which are extremely effective.... We have presales experts for all the demos and product expertise. We have value engineers who are more type of maturity who can use business case analysis for industries. We have industry principals who are industry experts working in various industries who can evangelize the trends and what is going on in the industry to speak head to head with key guys in the customer. We have maintenance and education and sales guys who are able to conduct special education services and maintenance to the customer, and all this needs to be managed by the account executive in a specific way. Of course, we also have the line of business solution specialists who are experts in one of our 3000 solutions, who have a more solution specific focus, rather than an industry 
focus. That is what IT company is when we talk about sales. It is quite a complex ecosystem of experts...." (Sales Manager/Europe)

Our qualitative analysis led to the following construct definition for this leader behavior: collaborating behavior by sales managers is organizing, facilitating, and leading group activities in which the salespeople were encouraged to interact with and learn from each other as they solve problems as a team.

Championing: An important aspect of expanding indirect and direct networks in the sales ecosystem occurs when a sales manager uses the championing behavior. The championing behavior is necessary because salespeople interact closely with customers and business partners and thus gain a significant amount of marketplace knowledge that is useful to the planning function of the organization (Bass, 1997). Consequently, non-sales coworkers from multiple divisions throughout the firm can make information requests from salespeople. Responding to all these requests can distract the sales team from their core job - selling. Salespeople discussed how they need shelter from these types of requests and valued sales managers that engaged in protecting, clearing roadblocks, obtaining approvals, and reducing administration. Salespeople also appreciated sales managers who champion causes and break down internal barriers for their salespeople and expand both their internal and external networks within the sales ecosystems. Thus, the championing leader behavior emerged as both necessary and important. Interestingly, existing leadership theories in organizational behavior do not mention championing; and this leader behavior has rarely been studied in sales management research (Peesker et al., 2019).

As with collaborating behaviors, championing involves coordination of multiple microsystems; so, it impacts the mesosystem of a salesperson. In a sense, however, these two leader behaviors work in an opposite manner. That is, collaboration is focused on bringing in other microsystems that can help salespeople be successful. Championing, on the other hand, is focused on protecting salespeople from unnecessary microsystems that might interfere with their development. Note that many of these unnecessary microsystems are associated with non-sales personnel within the company. The following comment echoes the point of how championing can protect salespeople:

"As a manager my task is to be the snow plough to run in front of you, the sales rep, and clean out the clutter and help you have as much time as possible with the client and do what you do best. That's possibly half of the snow plough. The other one is about enabling focus so that they can focus their time". (Sales Manager/Europe)

In other words, the championing behavior helps create an effective sales ecosystem by clearing road blocks, providing internal escalations, reducing administration, and assisting with problem solving. Respondents expressed the view that sales managers who engaged in this behavior could have a positive impact on developing salespeople and enabling performance.

Our qualitative analysis led to the following construct definition for this leader behavior: championing behavior by sales managers is intervening on behalf of their subordinate salespeople in a way that protects these salespeople from tangential and/or nonessential work tasks so that they can better focus on activities that are directly related to sales performance.

\section{Contrasting sales manager and salespeople perceptions}


The literature review suggested that sales managers and salespeople do not always view their environment in the same manner (DeCarlo et al., 1999). In the sales literature and in the leadership literature there have been calls for the examination of leadership from the perspectives of both sales managers and salespeople, particularly in relation to sales management and salesperson interactions (Schwepker, Jr. and Good, 2010). Similarly, in the leadership field, it has been proposed that researchers should consider the relationship of the leaders and followers rather than focusing on the separate identities of the individuals in the relationship (Ladkin, 2010). Indeed, the exploration of the sales management phenomenon from the perspective of both the sales manager and the salesperson has been called out as a critical requirement for the field (Deeter-Schmelz et al., 2008).

The present study responds to this call and, building on Deeter-Schmelz et al. (2008) which examined the leadership characteristics of sales managers from the perspective of salespeople and sales managers, extends it through the consideration of leadership behaviors and microsystems in a world that looks very different from 2008. Furthermore, taking the perspective of both the leader and subordinate allowed for the exploration of sales management/salesperson interactions, responding to Schwepker, Jr. and Good's (2010) call. Capturing both perspectives has led to new insights and contributions to the field.

Connections can be made from the present study to previous findings regarding high sales performers and time spent on sales activities and with customers. Brashear et al. (1997) found that high sales performers reported higher mean levels of the sales activities of selling and servicing customers. These researchers identified that more hours spent on performing sales activities, and more time invested in direct selling activity, produced improved sales results. This is relevant because the high performing salespeople in our study referred to the need for customer engaging leader behavior more frequently than did low performers. They also referred more frequently (although to a lesser extent) to the championing behavior than did low performers. The high performers suggested that these specific leader behaviors (customer engaging and championing), which enable the salespeople to spend more hours selling and servicing customers, will lead to enhanced sales performance. A contribution of this present research is to take a step back and define these two specific sales leader behaviors for sales managers to use with their sales team.

This research also connects to previous sales management literature about the coaching leadership behavior. In a conceptual article, Rich (1998) argued that coaching enhances performance when sales managers who are role models provide individualized feedback to their salespeople in an environment of mutual trust and respect. Supporting these linkages, the present study finds that high performers are not only more than twice as likely to reference coaching as compared to low performers, they also are much more likely to discuss the importance of trust. In fact, trust emerged as the number one relational element.

Interestingly, Brashear et al. (1997) found that relative to high performers, low performers focused more on prospecting and planning activities - suggesting that low performers engage in avoidance behaviors because of fear of failure. The present study connects to this claim in that high performers referred more frequently to confidence and resilience than did the low performers. That is, it follows that salespeople who are more confident and resilient would be less preoccupied with fear of failure. 


\section{The interaction between the sales manager and the salesperson}

Our analysis also produced intriguing findings regarding the interactions or relationships between the sales manager and salesperson, particularly in relation to the response of the salespeople to the leader behaviors of their sales managers. This is revealed through our comparison between the responses of high versus low performing salespeople. The top performing salespeople felt that their sales manager's leadership gave them confidence, optimism and resilience, three elements of psychological capital discussed in Authentic Leadership (Northouse, 2016). In contrast, the low performing salespeople focused primarily on trust.

Although this intriguing finding was not the focus of our research, we speculate as follows. It appears that high performers may have established stronger trust in their leader and, as a result, the sales manager is able to influence their psychological capital in a positive manner. By contrast, it appears that low performers have not established the same level of trust and therefore managers do not play the same role in enhancing their psychological capital; or at least to the same extent. Our data suggest that trust leads to higher quality of interactions and connections between salespeople and sales managers in a given microsystem.

Overall, identifying these relational elements provides a better understanding of the process of how coaching, collaboration, championing, and customer engagement enable salesperson performance. Trust, which was the most commonly referenced term by our respondents, is the one we feel most strongly contributes toward the effective functioning of a microsystem. This finding supports the work of Strutton et al. (1993) who encourage sales managers to create trustfacilitating psychological climates. As a result, we suggest that trust enhances both the quantity and quality of interactions and connections among individuals in a given microsystem.

Our research has focused on the sales ecosystem of a global technology company, the same context of a number of other influential studies on business ecosystems. Even though there were different national cultures among the sales professionals that we interviewed, we found that the responses about leadership appeared universal. Given the small sample size, it is difficult to find much meaning in this. However, we speculate that the pervasive culture of our research organization ('IT company') more than offset the different national contexts.

\section{Managerial Implications}

The managerial implications of this research are substantial. First, the study identifies four leader behaviors (coaching, customer engagement, collaborating and championing) that sales managers should be trained in and encouraged to use when managing across cultures. Past research has found that sales organizations too often neglect managerial training (Reid et al., 2017). This study provides a structure for sales organizations to develop and implement leadership training programs for their sales managers.

This research also indicates that, for the entire ecosystem of their sales force, sales managers will improve the performance of their salespeople by focusing on building connections and relationships across multiple salesperson microsystems. This is a unique perspective as it points to the importance of the broader environment (or ecosystem), rather than a focus on the individual outcome variables for each salesperson. Given that each salesperson has multiple 
microsystems and one mesosystem (the interaction of their microsystems), sales people may more quickly develop into high performers to the extent that all of the microsystems work well together; the sales manager can play a key role in making this happen through their leadership behaviors such as collaborating and coaching.

The study also identifies trust, confidence, optimism, and resilience as relational elements that may play important roles inside sales ecosystems. In particular, trust appears to play a role in the functioning of the connections and relationships that make up the microsystems. As Bennis and Nanus (1985, p. 43) observed, "Trust is the lubrication that makes it possible for organizations to work." Our research indicates that sales managers play a central role in creating a culture of mutual respect and trust among the salespeople within their ecosystem. When such a culture exists within the ecosystem, salespeople are more likely to share with and learn from each other (Schwepker, 2015). As this sharing increases, ecological systems theory (Bronfenbrenner, 1979) posits that development is enhanced.

\section{Limitations}

This study is subject to several limitations, including issues of reliability and validity that are characteristic of exploratory research analyzing qualitative data (Partington, 2002). To mitigate this risk, we followed established procedures by Miles and Huberman (1994). Indeed, a strong coder agreement (75\%) indicated that bias was negligible. Responding to calls from previous research to investigate complex business-to-business sales environments (Arnold et al., 2009; Bass, 1997; MacKenzie et al., 2001), the study interviewed salespeople from a single company in the highly relational software industry. Moreover, the sample is international, with respondents from 12 countries spanning four major regions of the world. Consequently, the context may not be representative of other sales ecosystems - such as transactional, business-toconsumer sales environments with lower-value products. Finally, the study compared high performing versus low performing salespeople, categories that were based on sales manager rankings of their salespeople's performance on attaining sales quotas. These rankings may have contained an element of subjectivity. We were not able to check for subjectivity because the company's sales performance data were strictly confidential.

\section{Opportunities for future research}

Several future research directions have emerged from the results of this study. Given the findings regarding leadership behaviors and salesperson performance in ecosystems, future research might examine perceptions of the sales leadership behaviors identified here across a wider range of sales professionals, extending the research to include other selling organizations and countries to consider the generalizability of the findings. This study focused on a single - albeit very large - international organization. More research would be needed to establish whether and to what extent these behaviors are characteristic of other sales contexts and systems, across different cultures and different industry sectors. Future studies could examine cross-cultural differences and similarities, to understand whether these sales leadership behaviors and the impact on their ecosystems are consistent globally, or if variations in emphasis exist in different regions of the world or in differing sectors. 
The current study focused predominantly on the first two levels of Bronfenbrenner's (1979) framework - microsystems and mesosystems. Future research could examine how sales organizations might enhance the relationship that sales representatives have with the other three levels of the ecosystem (exosystems, macrosystems, and chronosystems) in a way that leads to greater performance by the sales team. For example, future research could look at the effect of different macrosystem relationships (i.e. between the individual and societal institutions such as the government) on the effectiveness of sales leadership behavior.

Alternatively, future research might extend this study to examine the championing behavior identified in this study and to consider other intraorganizational microsystems where the central focus is the sales manager. These microsystems could include those focused on sales managers' relationships with their peers (i.e., other sales managers), with marketing professionals, and/or with c-suite executives in their organization. Future research might consider how these intraorganizational interactions influence the operation of the sales ecosystem.

This research has revealed some differences in preferred managerial leadership behaviors by high- and low- sales performers. An interesting direction for further study would be whether the effectiveness and functioning of a sales ecosystem can be strategically improved over time by managing the sales manager behaviors outlined above and also exploring any moderating effects within and outside the ecosystem. For example, how do the microsystems differ across career stages? That is, do newly hired, inexperienced salespeople differ from those that have been with the sales organization for many years?

Furthermore, future research could focus on microsystems and mesosystems that are centered on the relationships between salespeople and their customers - as opposed to the current study's focus on relationships between salespeople and their managers. This could be interesting from a variety of perspectives. For example, consumer behavior research has established that satisfied customers are more likely to recommend products to their friends through word of mouth (e.g., De Matos and Rossi 2008). The findings of this research could extend current research by taking an ecosystem approach to examining word of mouth from global customers, specifically the attributes and the effects that global word of mouth has on the composition of their ecosystem and their salesperson's effectiveness within that system.

\section{Conclusion}

This study applies ecosystems thinking to gain a better understanding of how sales managers can utilize leader behaviors to enhance the ecosystem associated with their salespeople. Analyzing qualitative data from in-depth interviews with 36 sales professionals, we find that four leader behaviors are especially effective in this regard. Specifically, we find that sales managers can and should engage in coaching and customer engagement (likely to enhance the microsystems of their salespeople) and engage in collaborating and championing (likely to enhance the mesosystems of their salespeople). The research is the first to explore an ecosystems approach to sales manager behaviors and differential sales performance levels in a global context. 


\section{References}

Adomavicius, G., Bockstedt, J., Gupta, A., \& Kauffman, R. J. (2006). "Understanding patterns of technology evolution: An ecosystem perspective", In Proceedings of the 39th Annual Hawaii International Conference on System Sciences, Vol. 8, pp. 189a-189a.

Anggraeni, E., Den Hartigh, E., \& Zegveld, M. (2007). "Business ecosystem as a perspective for studying the relations between firms and their business networks", ECCON 2007 Annual meeting, pp. 1-28.

Arnold, T.J., Palmatier, R.W., Grewal, D. and Sharma, A. (2009), "Understanding retail managers' role in the sales of products and services", Journal of Retailing, Vol. 85 No. 3, pp. 129-144.

Bande, B., Fernández-Ferrín, P., Varela-Neira, C., \& Otero-Neira, C. (2016). "Exploring the relationship among servant leadership, intrinsic motivation and performance in an industrial sales setting”, The Journal of Business \& Industrial Marketing, Vol. 31 No. 2, pp. 219-231.

Baruch, Y., Altman, Y., \& Tung, R. L. (2016). "Career mobility in a global era: Advances in managing expatriation and repatriation", Academy of Management Annals, Vol. 10 No. 1, pp. 841-889.

Bass, B. M. (1985), Leadership and Performance Beyond Expectations, Free Press, London; New York, NY.

Bass, B. M. (1997), "Personal selling and transactional/transformational leadership", Journal of Personal Selling \& Sales Management, Vol. 17 No. 3, pp. 19-28.

Bennis, W.G. and Nanus, B. (1985), Leaders: The Strategies for Taking Charge, First edn, Harper \& Row, New York.

Boehnke, K., Bontis, N., DiStefano, J. J. and DiStefano, A. C. (2003), “Transformational leadership: an examination of cross-cultural differences and similarities", Leadership and Organization Development Journal, Vol. 24 No. 1, pp. 5-15.

Bogers, M., Sims, J. and West, J. (2019), "What is an ecosystem? Incorporating 25 years of ecosystem research", Academy of Management Annual Meeting Proceedings, Vol. 2019 No. 1, pp. 11080.

Bolander, W., Santornino, C., Hughes, D. E. and Ferris, G. R. (2015), "social networks within sales organizations: Their development and importance for salesperson performance", Journal of Marketing, Vol. 79 No. 6, pp. 1-16.

Brashear, T. G., Bellenger, D. N., Barksdale, H. C. and Ingram, T. N. (1997), "Salesperson behavior: Antecedents and links to performance", Journal of Business \& Industrial Marketing, Vol. 12 No. 3-4, pp. 177-184.

Bronfenbrenner, U. (1979), The Ecology of Human Development: Experiments by Nature and Design, Harvard University Press, Cambridge, MA. 
Brown, M. E., Trevino, L. K. and Harrison, D. A. (2005), "Ethical leadership: A social learning perspective for construct development and testing", Organizational Behavior and Human Decision Processes, Vol. 97 pp. 117-134.

Charmaz, K. (2006), Constructing Grounded Theory: A Practical Guide through Qualitative Research, Sage, London, England.

Churchill, G., Ford, N., Hartley, S., \& Walker, O. (1985). "The Determinants of Salesperson Performance: A Meta-Analysis", Journal of Marketing Research, Vol. 22 No. 2, pp. 103-118.

Creswell, W. (2013). Qualitative inquiry and research design: Choosing among five approaches, Sage, Thousand Oaks, CA.

Dansereau, F. Jr., Graen, G. and Haga, W. J. (1975), "A vertical dyad linkage approach to leadership within formal organizations: A longitudinal investigation of the role making process", Organizational Behavior \& Human Performance, Vol.13 No. 1, pp. 46-78.

DeCarlo, T. E., Rody, R. C. and DeCarlo, J. E. (1999), “A cross national example of supervisory management practices in the sales force", Journal of Personal Selling \& Sales Management, Vol. 19 No. 1, pp. 1-14.

Deeter-Schmelz, D. R., Goebel, D. J. and Kennedy, K. N. (2008), "What are the characteristics of an effective sales manager? An exploratory study comparing salesperson and sales manager perspectives", Journal of Personal Selling \& Sales Management, Vol. 28 No. 1, pp. 7-20.

De Matos, C. and Rossi, C.A.V. (2008), "Word-of-mouth communications in marketing: A meta-analytic review of the antecedents and moderators", Journal of the Academy of Marketing Science, Vol. 36 No. 4, pp. 578-596

Dixon, A. and Tanner, J. F. (2012), "Transforming selling: Why it is time to think differently about sales research", Journal of Personal Selling \& Sales Management, Vol. 32 No. 1, pp. 9-13.

Easterby-Smith, M., Thorpe, R. and Jackson, P. R. (2008), Management Research, 3rd ed., Sage, London, England.

Eckhardt J.T, Ciuchta, M. P., and Carpenter, M. (2018), “Open innovation, information, and entrepreneurship within platform ecosystems", Strategic Entrepreneurship Journal, Vol. 12 No. 3, pp. 369-391.

Flynn, J. F. (2003), "How much should I give and how often? The effects of generosity and frequency of favor exchange on social status and productivity", The Academy of Management Journal, Vol. 46 No. 5, pp. 539-553.

Fontana, A. and Frey, J. H. (1994), "Interviewing: The art of science”, in Denzin, N. K. (ed.) and Lincoln, Y. S. (ed.), Handbook of Qualitative Research, Sage, Thousand Oaks, CA, pp. 361-376.

Guarte, J. M. and Barrios, E. B. (2006), "Estimation under purposive sampling”,

Communications in Statistics -- Simulation and Computation, Vol. 35 No. 2, pp. 277-84.

Hackman, R. J. and Oldham, G. R. (1974), The Job Diagnostic Survey: An Instrument for the Diagnosis of Jobs and the Evaluation of Job Redesign Projects, Department of Administrative Sciences: Yale University, New Haven, CT. 
Hartmann, N.N., Wieland H., and Vargo, S.L. (2017), From the Dyad to the Service Ecosystem: Broadening and Building Theory in Sales-An Abstract. In: Rossi P. (eds) Marketing at the Confluence between Entertainment and Analytics. Developments in Marketing Science: Proceedings of the Academy of Marketing Science. Springer, Cham, Switzerland.

Houston, F. S., Gassenheimer, J. B. and Moskulka, J. M. (1992), Marketing exchange transactions and relationships, Quorum Books, Westport, CT.

Howell, J. M. and Avolio, B. J. (1993), "Transformational leadership, transactional leadership, locus of control, and support for innovation", Journal of Applied Psychology, Vol. 78 No. 6, pp. 891-902.

Iansiti, M., and Levien, R. (2004). The keystone advantage: what the new dynamics of business ecosystems mean for strategy, innovation, and sustainability. Harvard Business Press, Cambridge, MA.

Ingram, T. N., LaForge, R. W., Locander, W. B., MacKenzie, S. B. and. Podsakoff, P. M. (2005), "New directions in sales leadership research", Journal of Personal Selling \& Sales Management, Vol. 25 No. 2, pp. 137-54.

Inyang, A. E., Agnihotri, R., \& Munoz, L. (2018). "The role of manager leadership style in salesperson implementation of sales strategy: A contingency perspective”, Journal of Business \& Industrial Marketing, Vol. 33 No. 8, pp. 1074-1086

Jacobides, M. G., Cennamo, C., \& Gawer, A. (2018). "Towards a theory of ecosystems”, Strategic Management Journal, Vol. 39 No. 8, pp. 2255-2276.

Kapoor, R. (2018), “Ecosystems: Broadening the locus of value creation”, Journal of Organization Design, Vol. 7 No. 1, pp. 1-16.

Ladkin, D. (2010), Rethinking Leadership: A New Look at Old Leadership Questions, Edward Elgar Publishing, Cheltenham, England.

Lee, J.Y. and Welliver, M.C. (2018), "The role of strategic leadership for learning on the relationship between training opportunities and salesperson job performance and commitment", European Journal of Training and Development, Vol. 42 No. 9, pp. 558-576.

Liden, R. C., Wayne, S. J., Zhao, H. and Henderson, D. (2008), “Servant leadership:

development of a multidimensional measure and multi-level assessment", Leadership Quarterly, Vol. 19, pp. 161-177.

Lincoln, Y. S. and Guba, E. G. (1985), Naturalistic Inquiry, Sage, Beverly Hills, CA.

MacKenzie, S. B., Podsakoff, P. M. and Rich, G. A. (2001), "Transformational and transactional leadership and salesperson performance", Journal of the Academy of Marketing Science, Vol. 29 No. 2, pp. 115-34.

Miles, M. B. and Huberman, A. M. (1994), Qualitative Data Analysis, 2nd ed., Sage, Thousand Oaks, CA. 
Moore, J.F. (1996), The Death of Competition: Leadership and Strategy in the Age of Business Ecosystems, 1st ed., HarperBusiness, New York, NY.

Northouse, P. G. (2016), Leadership Theory and Practice, 6th ed., Sage, Thousand Oaks, CA. Partington, D. (2002). Essential skills for management research, Sage, Thousand Oaks, CA.

Peesker, K.M., Ryals, L.J., Rich, G.A. and Boehnke, S.E. (2019), "A qualitative study of leader behaviors perceived to enable salesperson performance", Journal of Personal Selling and Sales Management, Vol. 39 No. 4, pp. 319-333.

Rapp, A. A., Petersen, J. A., Hughes, D. E., \& Ogilvie, J. L. (2020). "When time is sales: The impact of sales manager time allocation decisions on sales team performance", The Journal of Personal Selling \& Sales Management, Vol 40 No. 2, pp.132-148.

Reid, D. A., Plank, R. E., Peterson, R. M. and Rich, G. A. (2017), "Examining the use of sales force management practices", Journal of Business \& Industrial Marketing, Vol. 32, No. 7, pp. 974-986.

Rich, G. A. (1998), "The constructs of sales coaching: Supervisory feedback, role modeling and trust”, Journal of Personal Selling \& Sales Management, Vol. 18 No. 1, pp. 53-63.

Ritchie, J., Lewis, J., McNaughton-Nicholls, C. and Ormston, R. (2014), Qualitative research practice. 2nd ed. Sage, London, England.

Schwepker, C. H. (2015), "Influencing the salesforce through perceived ethical leadership: The role of salesforce socialization and person-organization fit on salesperson ethics and performance", Journal of Personal Selling \& Sales Management, Vol. 35 No. 4, pp. 292-313.

Schwepker, C. H. and Good, D. J. (2010), “Transformational leadership and its impact on sales force moral judgment”, Journal of Personal Selling \& Sales Management, Vol. 30 No. 4, pp. 299-317.

Shannahan, K. L., Bush, A. J. and Shannahan, R. J. (2013), “Are your salespeople coachable? How salesperson coachability, trait competitiveness, and transformational leadership enhance sales performance", Journal of the Academy of Marketing Science, Vol. 41 No. 1, pp. 40-54.

Sheth, J. (1996), "Organizational buying behavior: past performance and future expectations", Journal of Business \& Industrial Marketing, Vol. 11 No. 3/4, pp. 7-24.

Singh, R., Kumar, N. and Puri, S. (2017), "Thought self-leadership strategies and sales performance: integrating selling skills and adaptive selling behavior as missing links", Journal of Business \& Industrial Marketing, Vol. 32 No. 5, pp. 652-663.

Spigel, B. (2017). The relational organization of entrepreneurial ecosystems. Entrepreneurship Theory and Practice, Vol. 41 No.1, pp. 49-72.

Strauss, A. and Corbin, J. (1998), Basics of Qualitative Research: Grounded Theory Procedures and Techniques, 2nd ed., Sage, London, England.

Strutton, D., Pelton, L. E., \& Lumpkin, J. R. (1993). “The relationship between psychological climate and salesperson-sales manager trust in sales organizations", Journal of Personal Selling \& Sales Management, Vol. 13 No. 4, pp. 1-14. 
Turber, S., Brocke, J. and Gassman, O. (2015), "designing business models in the age of pervasive digitization", Academy of Management, Vol. 2015 No. 1, pp. 11600.

Turner, J. R., Baker, R., Schroeder, J., Johnson, K. R., \& Chung, C. (2018). “Leadership development techniques: Mapping leadership development techniques with leadership capacities using a typology of development", European Journal of Training and Development, Vol. 42 No. 9, pp. 538-557.

Üstüner, T. and Godes, D. B. (2006), "Better sales networks”, Harvard Business Review, Vol. 84 No. 7/8, pp. 102-112.

Vargo, S. L., \& Lusch, R. F. (2016). "Institutions and axioms: an extension and update of service-dominant logic", Journal of the Academy of Marketing Science, Vol. 44 No 1, pp. 5-23. 


\section{Table 1 References to leader behaviors}

\begin{tabular}{lc}
$\begin{array}{l}\text { Leader } \\
\text { Behaviors }\end{array}$ & $\begin{array}{c}\text { Total Number (\%) of } \\
\text { References }(\mathbf{n = 3 6})\end{array}$ \\
Coaching & $630(33.0 \%)$ \\
Collaborating & $387(20.3 \%)$ \\
Championing & $319(16.7 \%)$ \\
Customer Engaging & $230(12.1 \%)$ \\
Challenging & $98(5.1 \%)$ \\
Creating Vision & $91(4.8 \%)$ \\
Candidate Recruiting & $59(3.1 \%)$ \\
Inspiring & $55(2.9 \%)$ \\
Rewarding & $\underline{39(2.0 \%)}$ \\
\hline TOTAL NUMBER (\%) & $1,908(100 \%)$ \\
\hline
\end{tabular}

References by Sales
Managers $(\mathbf{n}=12)$ $312(39.9 \%)$

$137(17.5 \%)$

$99(12.7 \%)$

$68(8.7 \%)$

$24(3.1 \%)$

$51(6.5 \%)$

$55(7.0 \%)$

$18(2.3 \%)$

$\underline{17(2.2 \%)}$

$781(100 \%)$

\section{References by \\ Salespeople $(n=24)$}

$318(28.2 \%)$

$250(22.2 \%)$

$220(19.5 \%)$

$162(14.4 \%)$

$74(6.6 / 5)$

$40(3.5 \%)$

$4(0.4 \%)$

$37(3.3 \%)$

$22(2.0 \%)$

$1,127(100 \%)$

Note: There were a total number of 1,908 references to leader behaviors made by the 36 respondents in the study. Of these references, 781 were made by the 12 sales managers and 1,127 were made by the 24 salespeople. 


\section{Table 2 Sample Quotes of the Four Relational Elements}

- Trust: "On the other side, trust is a very good one. Trust your guys, you hired them, so you know they're a good salesperson, and they're trustworthy, and they are not in this role because they cannot do anything. Give a little bit of trust .... That's why everyone is willing to step up a little bit more, because they feel secure". (Salesperson/Europe)

- Confidence: "Would it help if a sales leader was able to do behaviors that enabled confidence? $100 \%$ yeah!! That's big. From sales there are a lot of rejections you can face from time to time, there's a lot of losses you may have throughout the course of your career. You may lose some big deals, you may lose deals and not understand why you lost them, because you think you did everything right in the book. I guess having a good sales leader with a lot of confidence and to give you that confidence saying no, you did a great job". (Salesperson/Commonwealth)

- Optimism: "You want to be optimistic about things. You want to see chances and opportunities, see the opportunities and not see the down side of things". (Salesperson/Europe)

- Resilience: "You have to be able to carry that thing forward and you know, be wanting to come back the next day and start again and try again. So it takes a lot of resilience and I think a big part of it is, for a sales manager to be feeding that energy to people, so that they are convinced they are doing the right things". (Salesperson/Asia Pacific) 
Table 3 Number (percent) of references between high and low performing salespeople

$\begin{array}{lcc}\begin{array}{l}\text { Leader } \\ \text { Behaviors }\end{array} & \begin{array}{c}\text { High Performing } \\ \text { Salespeople (n=8) }\end{array} & \begin{array}{c}\text { Low Perform } \\ \text { Salespeople (n }\end{array} \\ \text { Coaching } & 128(69 \%) & 57(31 \%) \\ \text { Collaborating } & 71(53 \%) & 63(47 \%) \\ \text { Championing } & 62(53 \%) & 56(47 \%) \\ \text { Customer Engagement } & 67(74 \%) & 24(26 \%) \\ \text { Challenging } & 17(44 \%) & 22(56 \%) \\ \text { Creating Vision } & 18(62 \%) & 11(38 \%) \\ \text { Inspiring } & 14(50 \%) & 14(50 \%) \\ \text { Rewarding } & 6(60 \%) & 4(40 \%) \\ \text { Candidate Recruiting } & 2(50 \%) & 2(50 \%) \\ & & \\ \text { Relational Elements } & & 11(38 \%) \\ \text { Trust } & 18(62 \%) & 2(12 \%) \\ \text { Confidence } & 15(88 \%) & 0(0 \%) \\ \text { Optimism } & 13(100 \%) & 1(11 \%) \\ \text { Resilience } & 8(89 \%) & \end{array}$


Figure 1 References to Leader Behaviors by High and Low Performing Salespeople

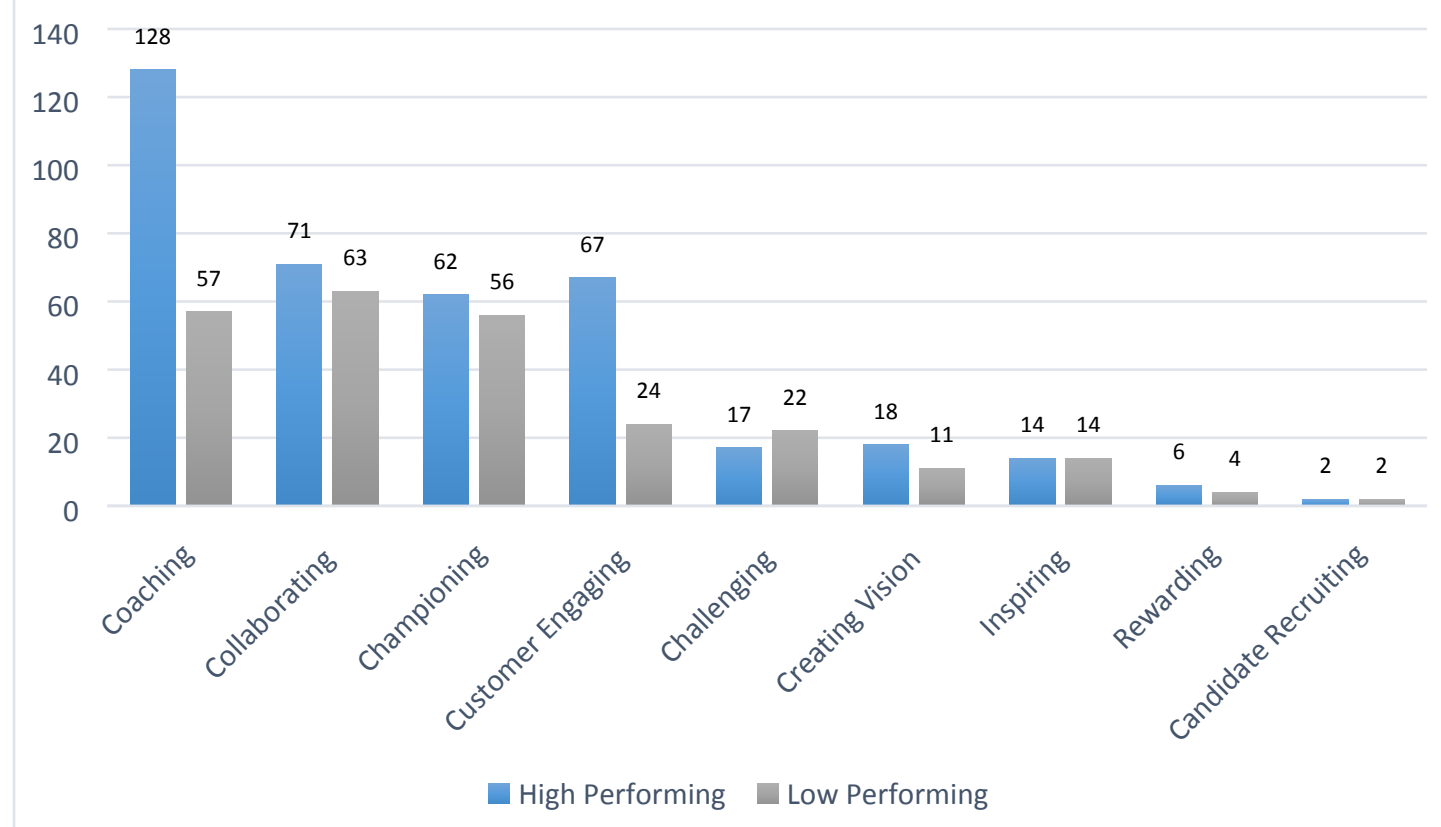


Figure 2 References to Relational Elements by High and Low Performing Salespeople

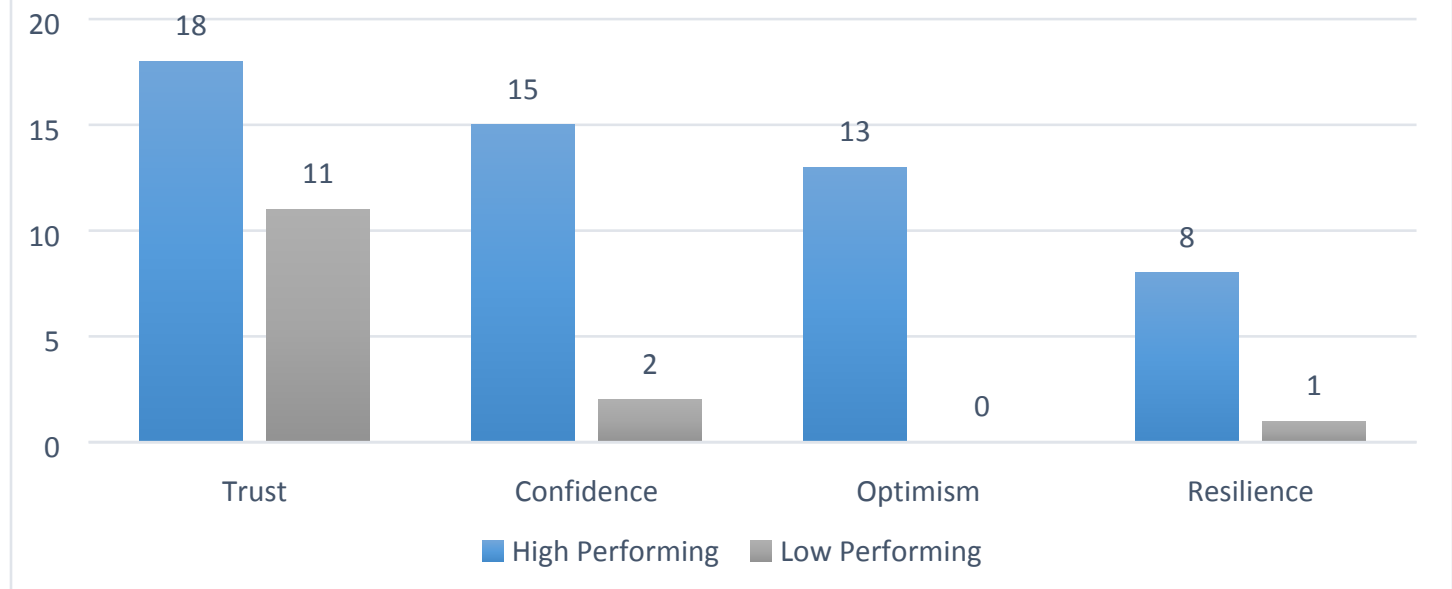


2021-01-13

\section{An ecosystems analysis of how sales managers develop salespeople}

Peesker, Karen M.

Emerald

Peesker K, Ryals L, Rich G, Davis L. (2021) An ecosystems analysis of how sales managers develop salespeople. Journal of Business and Industrial Marketing, Volume 36, Issue 4, May 2021, pp. 654-665

https://doi.org/10.1108/JBIM-01-2020-0037

Downloaded from Cranfield Library Services E-Repository 